Article

\title{
Dextran: Influence of Molecular Weight in Antioxidant Properties and Immunomodulatory Potential
}

\author{
Vinicius C. Soeiro ${ }^{1}$, Karoline R. T. Melo ${ }^{1}$, Monique G. C. F. Alves ${ }^{1}$, Mayara J. C. Medeiros ${ }^{2}$, \\ Maria L. P. M. Grilo ${ }^{1}$, Jailma Almeida-Lima ${ }^{1}$, Daniel L. Pontes ${ }^{2}$, Leandro S. Costa ${ }^{1,3}$ \\ and Hugo A. O. Rocha ${ }^{1, *}$ \\ 1 Departamento de Bioquímica, Universidade Federal do Rio Grande do Norte (UFRN), \\ Av. Salgado Filho 3000, Natal-RN 59078-970, Brazil; vihcampelo@gmail.com (V.C.S.); \\ melo.krt@gmail.com (K.R.T.M.); monique.gabi@gmail.com (M.G.C.F.A.); \\ mlporpino@hotmail.com (M.L.P.M.G.); biolottus23@yahoo.com.br (J.A.-L.); \\ leandro-silva-costa@hotmail.com (L.S.C.) \\ 2 Instituto de Química (IQ), Universidade Federal do Rio Grande do Norte (UFRN), Av. Salgado Filho 3000, \\ Natal-RN 59078-970, Brazil; mayarajane20049@hotmail.com (M.J.C.M.); pontesdl@yahoo.com (D.L.P.) \\ 3 Instituto Federal de Educação, Ciência a Tecnologia do Rio Grande do Norte (IFRN), \\ Av. Planalto, Km 406-Planalto, Ceará-Mirim-RN 59580-000, Brazil \\ * Correspondence: hugo@cb.ufrn.br; Tel.: +55-84-3215-3416
}

Academic Editor: Ester Boix Received: 15 June 2016; Accepted: 9 August 2016; Published: 19 August 2016

\begin{abstract}
Dextrans ( $\alpha$-D-glucans) extracted from Leuconostoc mesenteroides, with molecular weights $\left(M_{\mathrm{W}}\right)$ of 10 (D10), 40 (D40) and 147 (D147) kDa, were evaluated as antioxidant, anticoagulant and immunomodulatory drugs for the first time. None presented anticoagulant activity. As for the antioxidant and immunomodulatory tests, a specific test showed an increase in the dextran activity that was proportional to the increase in molecular weight. In a different assay, however, activity decreased or showed no correlation to the $M_{\mathrm{W}}$. As an example, the reducing power assay showed that D147 was twice as potent as other dextrans. On the other hand, all three samples showed similar activity $(50 \%)$ when it came to scavenging the $\mathrm{OH}$ radical, whereas only the D10 sample showed sharp activity (50\%) when it came to scavenging the superoxide ion. D40 was the single dextran that presented with immunomodulatory features since it stimulated the proliferation $(\sim 50 \%)$ of murine macrophages (RAW 264.7) and decreased the release of nitric oxide ( 40\%) by the cells, both in the absence and presence of lipopolysaccharides (LPS). In addition, D40 showed a greater scavenging activity (50\%) for the hydrogen peroxide, which caused it to also be the more potent dextran when it came to inhibiting lipid peroxidation (70\%). These points toward dextrans with a $40 \mathrm{kDa}$ weight as being ideal for antioxidant and immunomodulatory use. However, future studies with the D40 and other similarly $40 \mathrm{kDa}$ dextrans are underway to confirm this hypothesis.
\end{abstract}

Keywords: $\alpha$-D-glucans; Leuconostoc mesenteroides; immunomodulatory activity; 40 kDa dextran; antioxidant activity

\section{Introduction}

Glucans are polysaccharides of D-glucose monomers linked by glycosidic bonds. Despite the concept, the definition of a glucan is not yet fully established since some authors still refer to heteropolysaccharides that are high in glucose content as glucans [1]. In spite of having a monotone monosaccharide composition in comparison to other polysaccharides, glucans show variation when it 
comes to their molecular weights, types of glycosidic links, anomeric configurations of the glucose residue and types and degrees of ramifications throughout their chain [2].

These biopolymers are synthesized mainly by fungi, bacteria, plants and algae [3]. In these organisms, glucans perform a widely structural role and are, in an array of cases, the most widely available component in the cellular walls [4]. It is worth highlighting that, in some cases, bacteria and fungi may use glucans as an energy source [5].

There are $\alpha$-, $\beta$ - and $\alpha \beta$-glucans. The most widely available are, however, $\alpha$ - and $\beta$-glucans [6]. $\beta$-glucans are described as presenting with structural variations in numeric correlation to the links between their monomers. Those can be type $\beta-(1 \rightarrow 3), \beta-(1 \rightarrow 4)$ or $\beta-(1 \rightarrow 6)$, with possible ramifications throughout the chain [7]. These polymers have been undergoing investigations as to their biological, physiological and pharmacological potentials both in vitro and in vivo. Data already point toward their possible use in treating different types of cancer due to their antitumor [8], anti-proliferative [9] and immune response modulating $[10,11]$ potential. In addition, the pharmacological potential of $\beta$-glucans may also be availed in other areas since they can behave as anti-nociceptive [12] and antioxidant [13] agents.

The $\alpha$-glucans whose monosaccharides present exclusively in the $\alpha$ configuration are widely used as an energy source for living organisms. As an example, one can cite the $\alpha$-glucans known as glycogen (a source of energy for animals) [14] and starch ( $\alpha$-glucan used as a source of energy by plants) [15]. However, $\alpha$-glucans can also present with other interesting properties such as anti-inflammatory, antimicrobial [16], immunomodulatory [17] and antioxidant [18]. Not all $\alpha$-glucans, however, have been extensively evaluated for their pharmacological potential. One example of that are the dextrans.

Several groups showed the relationship between molecular weight $\left(M_{\mathrm{W}}\right)$ and pharmacological activities of polysaccharides including fucans [19], alginates [20], hyaluronic acid [21] and glucans. For instance, Zho et al. [22], working with two $\beta$-glucans, showed that high molecular weight $\beta$-glucan $(552 \mathrm{kDa})$ inhibits differentiation of 3T3-L1 pre-adipocytes stronger than that of low molecular weight $\beta$-glucan (32 kDa). Dextran sulfates (DS) are also affected by their molecular weight, and DS with three different $M_{\mathrm{W}}(4,15$ and $40 \mathrm{kDa})$ were used as anti-aggregation agent on cell growth and monoclonal antibody $(\mathrm{mAb})$ production and the data showed that the $40 \mathrm{kDa}$ DS was the most effective in attenuating cell aggregation and showed the highest maximum $\mathrm{mAb}$ concentration [23]. However, there are no data regarding dextrans.

Dextrans are described as $\alpha$-glucans with type $\alpha-(1 \rightarrow 6)$ links in their main chains and type $\alpha-(1 \rightarrow 3)$ (the most common), $\alpha-(1 \rightarrow 4)$ or $\alpha-(1 \rightarrow 2)$ ramifications [24]. They also present with a variety of molecular weights going from 1 to $2000 \mathrm{kDa}$ [25]. These polymers are synthesized mainly by fungi and bacteria of the Leuconostoc genus [26]. However, very little is known of the biological activities of dextrans, and those that are known are described solely when the dextrans are associated with other molecules [27]. Dextrans with different molecular weights synthesized by Leuconostoc mesenteroides (L. mesenteroides) are produced in large quantities and obtained in a commercial fashion. However, to the best of our knowledge, there has not yet been a study to evaluate the pharmacological activities of these polymers. In this context, three dextrans with different $M_{\mathrm{W}}(10,40$, and $147 \mathrm{kDa})$ synthesized by the L. mesenteroides were obtained commercially and evaluated as to their antioxidant, immunomodulatory and anticoagulant activities.

\section{Results and Discussion}

\subsection{Glucan Characterization}

The glucans called D10, D40 and D147 were acquired commercially and the information made available by the company selling said glucans lead one to believe they are the same compound, being differentiated by the molecular weight each one presents. In this particular stance, D10 presents with $10 \mathrm{kDa}$, while D40 and D147 present with 40 and $147 \mathrm{kDa}$, respectively. We chose these dextrans because they represent dextran molecules with low, medium and high molecular mass, 
respectively, in agreement with other papers that evaluated the influence of the molecular weight in the polysaccharides activity [19-23]. In addition, we did not used dextrans of higher molecular weights like 300 or $500 \mathrm{kDa}$ or even higher because they showed very low water solubility, as well as because they could break during the tests and their fragments could alter the overall result. With the intent of confirming the identities of said glucans, as well as of verifying if any contamination has occurred by impurities that might mask results, we conducted a series of chemical analyses of infrared spectroscopy (FTIR).

\subsection{Glucan Fourier Transform Infrared Spectroscopy (FTIR) Analyses}

Fourier Transform Infrared Spectroscopy (FTIR) Analyses is a technique that can be executed rapidly and allows for trustworthy confirmation of the molecule identity. Therefore, to confirm that samples in fact are dextrans and pure the samples were submitted to FTIR analysis and the spectra obtained can be seen on Figure 1. As can be observed, regardless of molecular weight, glucans D10, D40 and D147 present with very similar spectra, which indicates they are the same compound. Another important fact is that the spectra obtained from the three samples are the same obtained from other glucans [28].

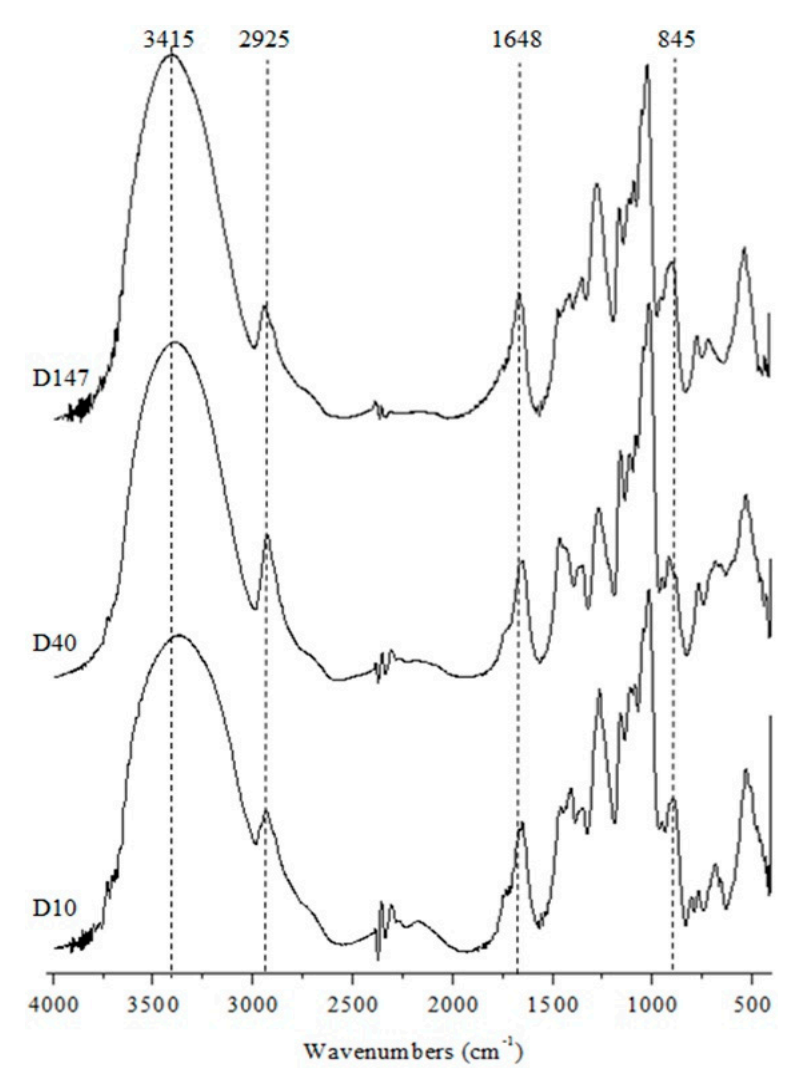

Figure 1. Fourier transform infrared spectroscopy (FTIR) spectra of the dextrans. The characteristics signals are in evidence for the regions between 4000 and $400 \mathrm{~cm}^{-1}$.

With regards to the main signals noted it can be observed that one strong band in the $3415 \mathrm{~cm}^{-1}$ region corresponds to the asymmetric stretching $\mathrm{O}-\mathrm{H}$ that overlaps itself over the hydrogen intramolecular link signals [29]. One signal between 2925 and $2932 \mathrm{~cm}^{-1}$ can be attributed to C-H symmetric and asymmetric stretching, respectively [17]. There is a signal in the region around $1648 \mathrm{~cm}^{-1}$ that corresponds to the water solvation layer around the polysaccharide [30]. These signals are characteristic to a number of polysaccharides such as chitosans [31], galactans [32], and glucans [33]. Other characteristic signals of glucans were identified, such as those on the 1457 and $1277 \mathrm{~cm}^{-1}$ regions 
that correspond to the signals of the glycosidic units, signal around $1156 \mathrm{~cm}^{-1}$ that corresponds to the $\mathrm{C}-\mathrm{O}-\mathrm{C}$ asymmetric stretching; signal around $\mathrm{cm}^{-1}$ that corresponds to $\mathrm{C}-\mathrm{C}$ [34]; and signals around 915 and $845 \mathrm{~cm}^{-1}$ that indicate the presence of $\alpha$-glycosidic links [35]. These signals were also identified in other dextran spectra [36] and, therefore, confirm the D10, D40 and D147 samples are dextrans. It is notable that no signs of protein content were found.

\subsection{Chemical Analyses}

All three samples, D10, D40 and D147, were analyzed as to the presence of contaminants: proteins and phenolic compounds. The data are available in Table 1. It can be observed that the presence of these was not identified in the samples. The information is important since both proteins and phenolic compounds are molecules that can influence in biological systems [37,38], which could create doubts as to possible activities that might come to be observed for the D10, D40, and D147 glucans.

As it relates to the total amounts of sugars, it was verified that D10, D40 and D147 possess an elevated amount of this compound ( $90 \%)$. It should be pointed out that the added percentage of total amounts of sugars, proteins and phenolic compounds does not account to 100 percent. This fact was also noted in the chemical composition analyses of other sugars such as ramnanas and fucans [39], and can be explained as decurrent from the hygroscopic property of polysaccharides since, even after lyophilization, they are capable of absorbing moisture from the environment extremely rapidly [40].

Table 1. Chemical composition of the D10, D40 and D147 dextrans.

\begin{tabular}{ccccccc}
\hline \multirow{2}{*}{ Dextrans } & \multirow{2}{*}{ Total Sugar (\%) } & \multirow{2}{*}{ Proteins (\%) } & \multirow{2}{*}{$\begin{array}{c}\text { Phenolic } \\
\text { Compounds (\%) }\end{array}$} & \multicolumn{3}{c}{ Molar Ratio * (\%) } \\
\cline { 6 - 7 } & & & nlc & Man & Gal \\
\hline D10 & 91.3 & n.d. & n.d. & $1: 0$ & $0: 0$ & $0: 0$ \\
D40 & 90.5 & n.d. & n.d. & $1: 0$ & $0: 0$ & $0: 0$ \\
D147 & 93.1 & n.d. & n.d. & $1: 0$ & $0: 0$ & $0: 0$ \\
\hline
\end{tabular}

Glc: glucose; Man: mannose; Gal: galactose. * Molar ratio obtained by high performance liquid chromatography (HPLC) analyses after acid hydrolysis $\left(\mathrm{HCl} 2 \mathrm{M} ; 2 \mathrm{~h} ; 100^{\circ} \mathrm{C}\right.$ ). n.d.: Not detectable in the evaluated conditions.

Dextrans used in the study are composed exclusively by glucose and, therefore, are homoglucans. Leuconostoc mesenteroides can synthesize, beyond dextrans, a small amount of heteroglucans that contain residue of mannose and galactose [34]. However, as we have not identified other monosaccharides besides glucose, we conclude that D10, D40 and D147 are dextrans with a high degree of purity.

\subsection{Antioxidant Activities}

Antioxidants are described mainly as low molecular weight molecules that have a protective effect both against non-reactive species, such as the hypochlorite, and against reactive oxygen species (ROS) and reactive nitrogen species (RNS) [41].

The formation process of these two reactive species is done through a chain reaction involving three steps (initiation, propagation and termination) in which the antioxidants take effect through a series of mechanisms. Thus, different methods were used to evaluate the effect of dextrans D10, D40 and D147 at the different stages: initiation (total antioxidant capacity and reducing power), propagation (chelation of copper and iron) and termination (scavenging of the hydroxyl superoxide radical and of the hydrogen peroxide). Moreover, the inhibiting lipid peroxidation of the dextrans was also determined.

\subsubsection{Chelating of Copper and Iron Ions Assay}

The D10, D40 and D147 dextrans presented with no chelating activity of $\mathrm{Fe}^{2+}$ and $\mathrm{Cu}^{2+}$ ions (Figure 2A,B). It was not possible to compare the results to those presented by other authors since no article was identified evaluating this specific activity in dextrans. With regards to other glucans, despite few records, it was verified that the activity occurs and that it is detached from the molecular 
weight, since $\alpha$-glucans of 9 and $113 \mathrm{kDa}$ extracted from Aconitum kusnezoffii Reichb tubers presented with a similar chelating activity for iron ions. However, it is noteworthy that the activity was only $10 \%$ [18]. Low chelating activity of iron was also identified in 5 and $15 \mathrm{kDa}$ dextrans extracted from the Ganoderma lucidum mushroom fruiting body. In this case, authors pointed out a chelating activity of $50 \%$. This activity was only achieved, however, when glucans were at a concentration of $10.0 \mathrm{mg} / \mathrm{mL}$ [42], meaning a much superior concentration in comparison to what was used in this paper. For comparison purposes, corncob xylans presented with a chelating iron activity around $80 \%$ in a $1.0 \mathrm{mg} / \mathrm{mL}$ concentration [43]. To summarize, data seen here lead to the proposition that metal chelating activity seems not to be the main antioxidant mechanism in glucans.

A

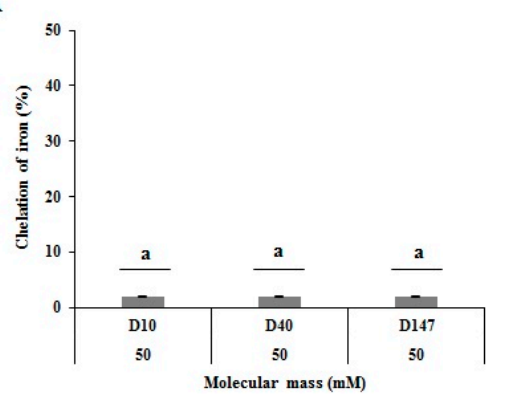

C

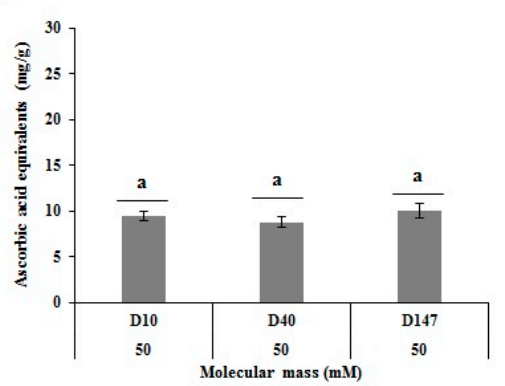

E

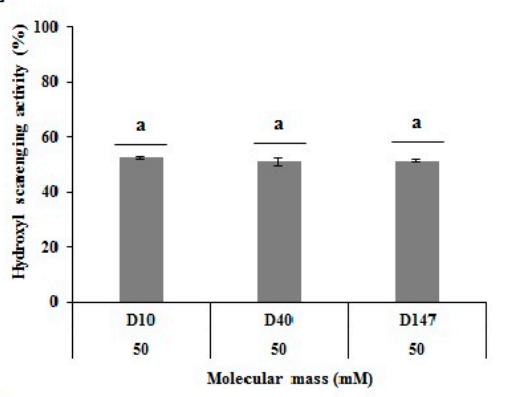

G

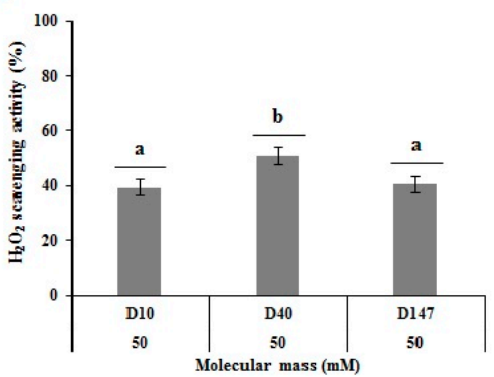

B

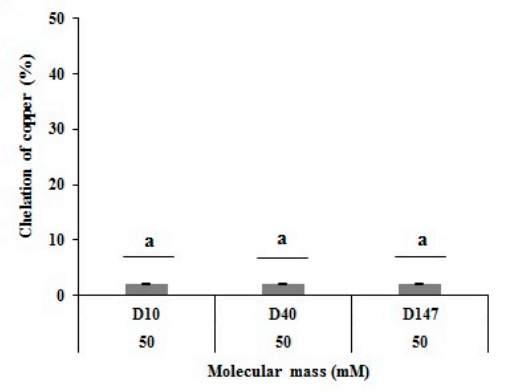

D

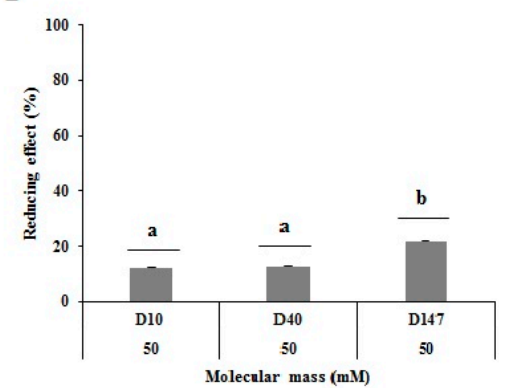

F

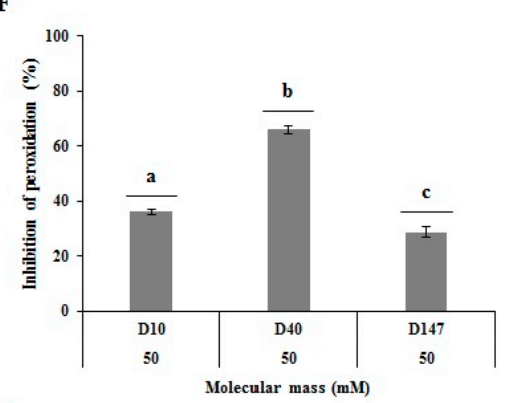

H

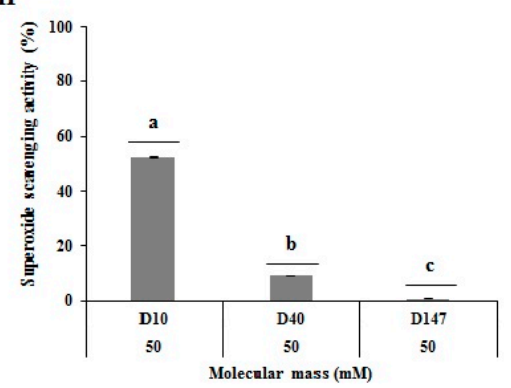

Figure 2. Antioxidant activities of D10, D40 and D147. (A) Ferrous chelating; (B) copper chelating; (C) total antioxidant capacity; (D) reducing Power; (E) hydroxyl radical scavenging; (F) inhibiting lipid peroxidation; $(\mathbf{G})$ hydrogen peroxide radical scavenging; and $(\mathbf{H})$ superoxide radical scavenging. Letters ${ }^{a, b, c}$ represent the significant difference between the samples by the simple variance analyses (one-way ANOVA) followed by the Tukey-Kramer $(p<0.05)$ test. 


\subsubsection{Reducing Power and Total Antioxidant Capacity (TAC) Assays}

Tested dextrans presented a total antioxidant capacity (TAC) around 9.8, 8.7 and 9.9 equivalent in ascorbic acid milligrams to D10, D40 and D147, respectively, which is the first report of glucans with a TAC activity (Figure 2C). In reducing power test, the data were expressed as percentage activity of ascorbic acid control at $0.1 \mathrm{mg} / \mathrm{mL}$. For the reducing power, dextrans D10 and D40 presented with $12.1 \%$ and $12.8 \%$ activity, respectively, while D147 reached a superior activity around $21 \%$ (Figure 2D). These reducing power values were similar to those obtained in other glucans, particularly $\beta$-glucans such as laminarin (extracted from the Laminaria digitate algae), botryosphaeran (extracted from the Botryosphaeria rhodina MAMB-05 fungi), curdlan (extracted from the Alcaligenes faecalis bacteria) and lasiodiplodan (extracted from the Lasiodiplodia theobromae MMPI fungi) [44].

In these two tests, one evaluates the samples' capacities to donate electrons in a solution. For the polysaccharides, the capacity was possibly connected to the presence of hydroxyls linked along the entire chain [39]. However, it can be observed that this capacity in dextrans, as in other molecules, is dependent on the experimental conditions since the TAC dextran tests present with a much smaller activity than the one observed in the reducing power test. The fact that the dextrans presented with reducing activity in two tests that have different chemical environments indicates these molecules can also present the activity in the different chemical microenvironments found inside the cells.

Specifically, in regards to the reducing power test, it was verified that the D147 dextran presented with double the activity of the other dextrans (D10 and D40), which indicates the reducing capacity of the dextrans is dependent on molecular weight. However, it is notable that no other studies that evaluated the correlation between molecular weight in glucans and reducing power were found. Therefore, it would be necessary for other studies with glucans of varied molecular weights be conducted to corroborate data found.

\subsubsection{Hydroxyl Radical Scavenging Assay}

Dextrans D10, D40 and D147 showed scavenging activity for hydroxyl ions of 50\% (Figure 2E). The activity was higher than the observed in a $\beta$-glucan obtained from the Dictyophora indusiata fungi, which was $\sim 39 \%$ of scavenging [45]. However, as it relates to molecular weight, it was possible to observe the activity in dextrans is not influenced by this property. This, in turn, corroborates data described by Hong and collaborators, which show $\beta$-glucans with very distinctive weights, such as 70 and $900 \mathrm{kDa}$ obtained from the Paenibacillus polymyxa JB115 bacteria, present with the same scavenging capacity for hydroxyl radicals [8].

\subsubsection{Inhibiting Lipid Peroxidation Assay}

When testing for the dextrans capacity to inhibit the lipid peroxidation it was observed that D10 and D147 presented with inhibiting capacity of $\sim 30 \%$, while D40 presented with an elevated capacity of $\sim 70 \%$. The amount obtained with $\mathrm{D} 40$ becomes significant when compared to those found in the literature (Figure 2F). For example, homoglucans extracted from the Ganoderma lucidum fungi inhibited the peroxidation by around 77\%, while heteroglucans extracted from the Agaricus bisporus fungi inhibited lipid peroxidation by merely $46 \%$. In both cases, however, values were only obtained at $20 \mathrm{mg} / \mathrm{mL}$ [46], which is much greater than the concentration used in our experiments. These authors also state that the difference between the two glucans occurred due to the difference in the monosaccharide composition, meaning the presence of other monosaccharides other than glucose would lead heteroglucans to being less effective. The data lead to the belief that homoglucans have a good potential to prevent lipid peroxidation.

Data also lead to the observation that dextrans are more active in certain molecular weights than in others, as if there were an ideal weight for a dextran that would lead it to show their maximum lipid peroxidation inhibition capacity, since D40 was much more effective than the other dextrans tested. In addition, one other dextran used in the clinic called Dextran 40 has already presented itself as a lipid peroxidation inhibition agent, and the molecular weight of this dextran is also approximately 
$40 \mathrm{kDa}$ [47]. New studies that compare other glucans with a molecular weight around $40 \mathrm{kDa}$ to glucans with larger or smaller weights will be able to confirm this hypothesis.

This lipid peroxidation inhibition capacity observed in the dextrans stands out since there is a clear correlation between aging, caused by the continuous and elevated exposure to reactive species, and lipid peroxidation. This correlation was made clear once the accumulation of lipofuscin, a pigment capable of detecting the presence of free radicals and lipid peroxidation, was observed in the development of atherosclerosis [48]. In addition, the increased formation of lipid peroxides is also observed in Alzheimer's disease, cancer, rheumatoid arthritis, and other immune diseases [49]. Therefore, inhibiting the lipid peroxidation could promote a certain protection to the body, once it is clearly related to the chain reaction that causes selective changes to the cell's signals, protein damage and DNA.

\subsubsection{Hydrogen Peroxide Radical Scavenging Assay}

With the intent of better understanding the dextran's capacity to inhibit the lipid peroxidation, an assay was conducted to measure the scavenging of hydrogen peroxide radicals, since this particular radical is closely related to reactions that form the peroxide radicals [44]. Dextrans D10 and D147 presented with a scavenging capacity of $\sim 40 \%$, while D40 showed a scavenging capacity of $50 \%$ (Figure 2G). This result was bigger than that obtained with $140 \mathrm{kDa}$ glucans extracted from the roots of Aconitum kusnezoffii Reichb, which presented with a 33\% capacity [18], as well as two glucans of 5 and $15 \mathrm{kDa}$ obtained from the Ganoderma lucidum fungi that showed a scavenging capacity of around 30\% [42]. However, we highlight the fact that, just as for the lipid peroxidation assay, the D40 dextran was more effective than the D10 and D147, which shows the main inhibition mechanism for lipid peroxidation in dextrans is in their capacity to scavenge the hydrogen peroxide.

\subsubsection{Superoxide Radical Scavenging Assay}

With regards to the dextran's capacity to scavenge the superoxide ions, it was observed that the activity decreases as the molecular weight of the dextran increases, since D147 presented with a $0.7 \%$ activity, D40 with $9 \%$ activity, and D10 presented with a $52.3 \%$ activity (Figure $2 \mathrm{H}$ ). The data corroborate Liu and collaborators observations that showed a $5.2 \mathrm{kDa}$ glucan from the G. lucidum fungi showed a scavenging activity of around $80 \%$, while only $~ 50 \%$ was obtained from a $15 \mathrm{kDa}$ from the same fungi [42].

In short, the data lead to the proposition that dextrans D10 and D40 are more promising molecules from an antioxidant point of view, when compared to the D147. In addition, still favoring D10 and D40, the search is always for lower molecular weight compounds since those are more easily absorbed and distributed inside the human system, metabolized and discarded in urine [50].

\subsection{3-(4,5-Dimethylthiazol-2-yl)-2,5-diphenyltetrazolium bromide (MTT) Mitochondrial Reduction Assay}

Dextrans D10, D40 and D147 allowed for an increase in the 3-(4,5-dimethylthiazol-2-yl)-2,5diphenyltetrazolium bromide (MTT) reducing activity in RAW 264.7 cells (murine macrophages) (Figure 3A). However, the effect was only significant in the presence of D40, which points to a mitosis action in the dextran. The data suggest that the dextrans in this study do not show cytotoxic activity to the cells. Other glucans are described as having a mitosis action in macrophages [5] and lymphocytes [18,51].

\subsection{The Effect of Dextrans in the Nitric Oxide Production in RAW Cells}

$\beta$-Glucans are cited as being immunomodulatory agents in a variety of studies $[44,51,52]$. However, there are few data regarding $\alpha$-glucans and we could not find any data referring to the evaluation of the immunomodulatory ability of dextrans. Since D10, D40 and D147 dextrans were not cytotoxic to RAW cells, it was evaluated if they would affect the production of nitric oxide by those cells, both in the presence and absence of LPS (a widely known macrophage activator). Data showed, however, that D10 and D147 dextrans did not affect the nitric oxide (NO) production by the RAW cells 
in every tested condition. On the other hand, D40 decreased $\sim 40 \%$ the amount of NO released by RAW cells, both in the presence and absence of LPS (Figure 3B).

A

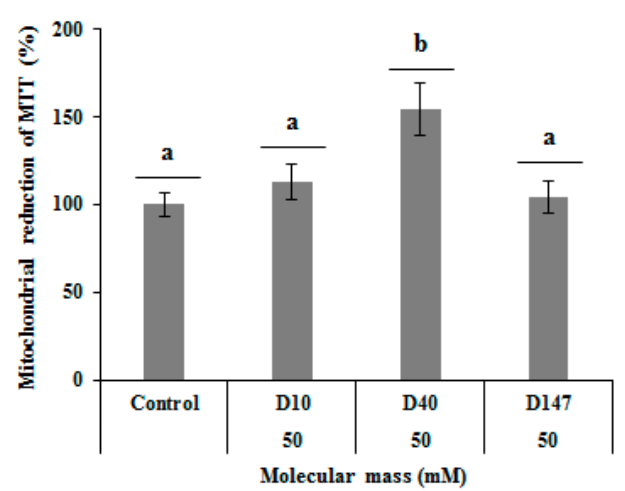

B

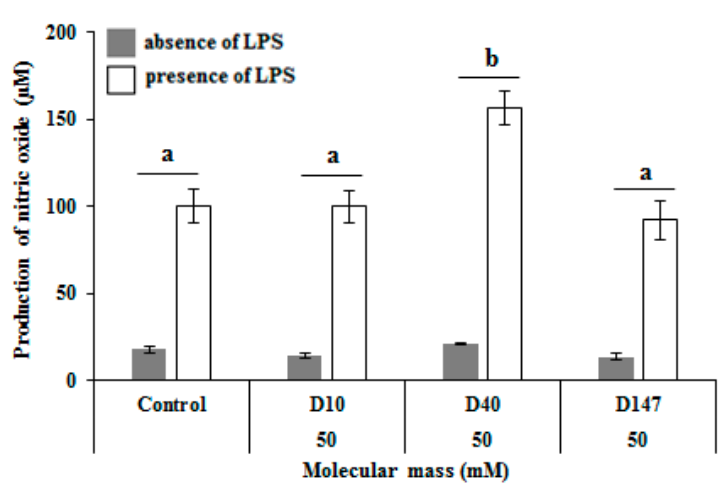

Figure 3. Effect of D10, D40 and D147 in RAW cells: (A) 3-(4,5-dimethylthiazol-2-yl)-2,5diphenyltetrazolium (MTT) mitochondrial reduction by cells in the presence of glucans; and (B) nitric oxide production by RAW cells in the presence of glucans. Letters ${ }^{a, b}$ represent the significant difference between the various samples according to the simple variation analyses (one-way ANOVA) followed by the Tukey-Kramer $(p<0.05)$ test. LPS, lipopolysaccharides.

In short, data obtained here lead to the observation that D10 and D147 dextrans are not immunomodulatory agents. However, D40 stimulates the proliferation of macrophages and inhibits the production of NO, which awards this dextran an immunomodulatory action. This also leads to the observation that, as well as for the antioxidant action, the dextrans with molecular weight around $40 \mathrm{kDa}$ will tend toward more noticeable action.

\subsection{Anticoagulant Activities (Activated Partial Thromboplastin Time (aPTT) and Prothrombin Time (PT))}

Dextrans D10, D40 and D147 did not show anticoagulant activity, neither in activated partial thromboplastin time (aPTT) nor prothrombin time (PT) assays (Figure 4A,B). These results corroborate with those observed in the PT and aPTT assays performed with $420 \mathrm{kDa} \beta$-glucan from lichen Parmotrema mantiqueirense Hale, which was also not able to induce any apparent coagulation. On the other hand, this glucan showed anticoagulant activity when it was sulfated [53]. The data found with dextran D10, D40 and D147 are positive because anticoagulant activity could be an obstacle to the use of these dextrans as antioxidant or immunomodulatory agents.
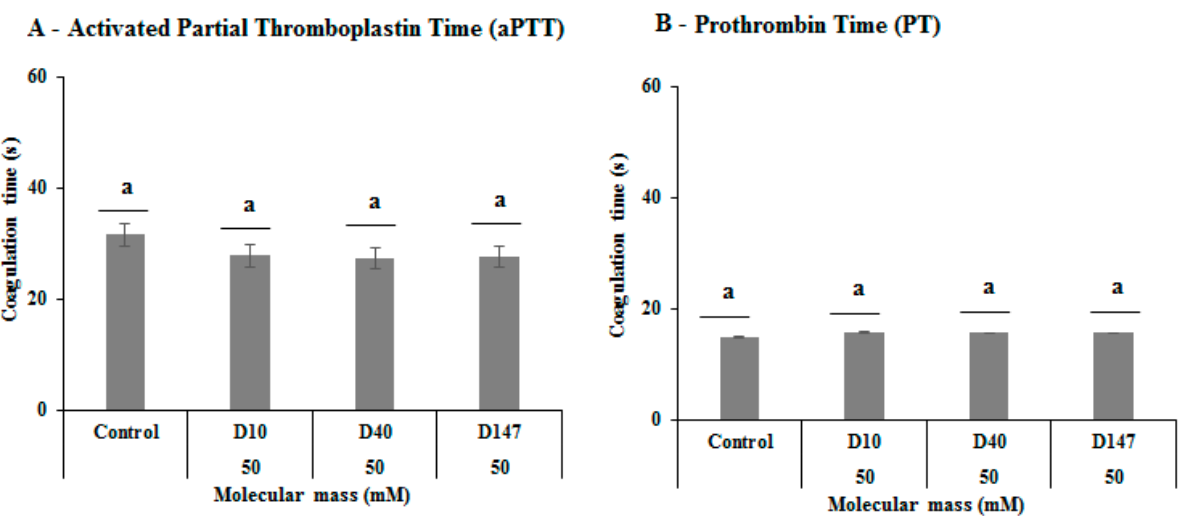

Figure 4. Anticoagulant activities of D1, D40 and D147: (A) activated partial thromboplastin time (aPTT); and (B) prothrombin time (PT). Letter a represent non-significant difference between the various samples according to the variation analyses (one-way ANOVA) followed by the Tukey-Kramer $(p<0.05)$ test. 


\section{Materials and Methods}

\subsection{Materials}

The 10, 40 and 147 kDa dextrans (Catalog number: 1179876, 1179865 and D-487); bovine serum albumin (BSA); sodium chloride; ferrozine; butylated hydroxyanisole (BHA); pyrocatechol violet; and ascorbic acid were purchased from Sigma Chemical Co. (St. Louis, MO, USA). Potassium ferricyanide, ferrous sulfate (II), ethylenediaminetetraacetic acid (EDTA), Gallic acid, ammonium molybdate, hydrogen peroxide 30\%, acetic acid, Folin-Ciocalteu phenol reagent, ethanol and sulfuric acid were obtained from Merck (Darmstadt, Germany). Culture media components Minimum essential Dulbecco's modified Eagle medium (DMEM), L-Glutamine, sodium pyruvate, sodium bicarbonate, non-essential amino acids, fetal bovine serum and phosphate buffered saline (PBS) were acquired from Invitrogen Corporation (Burlington, ON, Canada). All other reagents and solvents were of analytical degree.

\subsection{Fourier Transformed Infrared (FT-IR) Spectroscopy Analysis}

The infrared spectra of D10, D40 and D147 were obtained using infrared spectroscopy via Fourier transform (IRAffinity-1 spectrometer, Shimadzu Corp., Kyoto, Japan) equipped with the IRsolution 1.20 software. Samples were mixed completely with the dried potassium bromide powder $(\mathrm{KBr})$ and compressed. The sweep frequency range was $4000-400 \mathrm{~cm}^{-1}$. Representative spectra of three independent experiments are shown [54].

\subsection{Chemical Analysis and Monosaccharide Composition}

Total amounts of sugars, proteins and phenolic compounds were determined as described previously [55]. Total amounts of sugars were determined by the phenol- $\mathrm{H}_{2} \mathrm{SO}_{4}$ method using D-glucose as a standard. Amounts of proteins were measured by employing the Coomassie Brilliant Blue reagent, using bovine serum albumin (BSA) as a standard. Phenolic compounds were measured by the Folin-Ciocalteau phenol reagent method, using Gallic acid as a standard. The monosaccharide composition was verified by the acid hydrolysis of the polysaccharides using $\mathrm{HCl}$ in a variety of concentrations $(0.5,1.0,2.0$, and $4.0 \mathrm{M})$ for different periods $(0.5,1,2$, and $4 \mathrm{~h})$ at $100{ }^{\circ} \mathrm{C}$, as described by Camara and collaborators [30]. It was verified that $\mathrm{HCl}(2.0 \mathrm{M})$ for a period of $2 \mathrm{~h}$ was the best condition available to break down the polysaccharides without degrading the free monosaccharides in the sample. After the acid hydrolysis, the monosaccharide composition was determined by the VWR-Hitachi Lachrom Elite ${ }^{\circledR}$ HPLC system (Hitachi Co., Tokyo, Japan) with the refraction index detector. The LichroCART ${ }^{\circledR} 250-4(250 \mathrm{~mm} \times 40 \mathrm{~mm})$ column connected to a Lichrospher ${ }^{\circledR} 100 \mathrm{NH}_{2}$ $(5 \mu \mathrm{m})$ was then attached to the system. The concentration of the sample used was $50 \mathrm{mM}$ and the analysis time was $25 \mathrm{~min}$. The following sugars were used as reference: galactose, fucose, fructose, a rabinose, xylose, glucose and mannose.

\subsection{Antioxidant Activities}

The antioxidant activities were investigated through a series of eight in vitro assays: iron ion chelation, copper ion chelation, total antioxidant capacity (TAC), reducing power, hydroxyl radical scavenging activity, inhibiting lipid peroxidation, hydrogen peroxide scavenging activity and superoxide radical scavenging activity. All eight tests were conducted with the $50 \mathrm{mM}$ concentration for all samples. All assays were conducted three times, always in triplicate.

\subsubsection{Chelating of Iron}

The assay was conducted to investigate the sample's capacity to chelate iron ions as described earlier [30]. Briefly, the reaction containing ferrous chloride $(2 \mathrm{mM})$ and ferrozine $(5 \mathrm{mM})$ were mixed with the samples and incubated for $10 \mathrm{~min}$ at $25^{\circ} \mathrm{C}$. The change in color was measured in a microplate 
reader (BioTek, Winooski, VT, USA) at $562 \mathrm{~nm}$ against a blank. EDTA was used as positive control. The ability of the samples in chelating the iron ion was calculated using the following equation: [(Absorbance of blank - Absorbance of the sample)/Absorbance of the blank)] $\times 100$.

\subsubsection{Chelating of Copper}

The assay investigated the sample's capacity to chelate copper ions. Pyrocatechol violet, the reagent used in this assay, has the ability to associate with certain cations. In the presence of chelating agents, this combination is not formed, resulting in decreased staining. The test was performed in 96-well microplates with a reaction mixture containing the samples $(50 \mathrm{mM})$, pyrocatechol violet $(4 \mathrm{mM})$, and copper II sulfate pentahydrate $(50 \mathrm{mg} / \mathrm{mL})$. All wells were homogenized with the aid of a micropipette and the solution absorbance was measured at $632 \mathrm{~nm}$ against a blank [43]. EDTA was used as positive control. The ability of the samples in chelating the copper ion was calculated using the following equation: [(Absorbance of blank - Absorbance of the sample)/Absorbance of the blank) $] \times 100$.

\subsubsection{Total Antioxidant Capacity (TAC)}

The total antioxidant capacity assay consists of the reduction of the $\mathrm{Mo}^{+6}$ to $\mathrm{Mo}^{+5}$ ions by the samples and the subsequent formation of the phosphate-molybdate complex in low $\mathrm{pH}$ values. The dextrans and the reagent solution (sulfuric acid $0.6 \mathrm{M}$, sodium phosphate $28 \mathrm{mM}$ and ammonium molybdate $4 \mathrm{mM}$ ) were incubated at $95^{\circ} \mathrm{C}$ for $90 \mathrm{~min}$. immediately afterwards, the absorbing capacities of each solution were measured at $695 \mathrm{~nm}$ against the blank. The TAC was recorded as ascorbic acid milligrams/dextran grams, described as equivalent of ascorbic acid [55].

\subsubsection{Reducing Power}

The reducing power assay consists of the reduction of the potassium ferricyanide by the samples. Briefly, the dextrans were mixed with a phosphate buffer $0.2 \mathrm{M}(\mathrm{pH} 6.6)$ and incubated with potassium ferricyanide $(1 \% \mathrm{~m} / \mathrm{v})$ at $50{ }^{\circ} \mathrm{C}$ for $20 \mathrm{~min}$. One solution of trichloroacetic acid $(10 \% \mathrm{~m} / \mathrm{v})$ was used to stop the reaction. Distilled water and ferrous chloride $(0.1 \% \mathrm{~m} / \mathrm{v})$ were added to the solution and the absorbing capacities were measured at $700 \mathrm{~nm}$. Results were accounted as an activity percentage, considering the largest concentration of ascorbic acid (the standard) as 100\% activity [43].

\subsubsection{Hydroxyl Radical Scavenging Activity Assay}

The hydroxyl radical scavenging activity of the dextrans had its investigation based on the Fenton reaction. Hydroxyl radicals were generated by the reaction containing a sodium phosphate buffer $150 \mathrm{mM}$ (pH 7.4) mixed with ferrous sulfate heptahydrate $10 \mathrm{mM}$, ethylenediaminetetraacetic acid (EDTA) $10 \mathrm{mM}$, sodium salicylate $2 \mathrm{mM}$ and hydrogen peroxide $30 \%$. Hydrogen peroxide was replaced with phosphate buffer for the blank sample. The solutions were incubated at $37^{\circ} \mathrm{C}$ for $1 \mathrm{~h}$ and the scavenging capacity was detected via the absorbing capacity analysis at $510 \mathrm{~nm}$. The results were recorded as scavenging percentage [24]. Gallic acid was used as positive control.

\subsubsection{Inhibition of Lipid Peroxidation}

The assay investigated the oxidation of the $\beta$-carotene. Briefly, the dextrans were mixed with $0.5 \mathrm{mg}$ of $\beta$-carotene and chloroform, $25 \mu \mathrm{L}$ of linoleic acid and $200 \mathrm{mg}$ of Tween 40 . Initially, the chloroform was evaporated and $50 \mathrm{~mL}$ of distilled water saturated with $\mathrm{O}_{2}$ was added. The emulsions were incubated with the dextrans and the inhibition was detected by monitoring the absorbing capacities at $490 \mathrm{~nm}$. The reactive mixture was incubated at $50{ }^{\circ} \mathrm{C}$ for $2 \mathrm{~h}$ and once again the absorbing capacities were verified. Butylated hydroxyanisole (BHA) was used as positive control. The results were recorded as inhibition percentage [56]. 


\subsubsection{Hydrogen Peroxide Scavenging Activity Assay $\left(\mathrm{H}_{2} \mathrm{O}_{2}\right)$}

The assay was conducted to investigate the dextran's capacity to scavenge the hydrogen peroxide. Briefly, the reaction was to mix the dextrans with $100 \mathrm{~mL}$ of $\mathrm{H}_{2} \mathrm{O}_{2} 0.002 \%$. Then, $0.8 \mathrm{~mL}$ of sodium phosphate buffer $0.1 \mathrm{M}$ and sodium chloride $100 \mathrm{mM}$ were added. The solutions were incubated at $37^{\circ} \mathrm{C}$ for $10 \mathrm{~min}$. After that, $1 \mathrm{~mL}$ of the phenol red indicator $(0.2 \mathrm{mg} / \mathrm{mL})$ with $0.1 \mathrm{mg} / \mathrm{mL}$ of peroxidase in sodium phosphate buffer $0.1 \mathrm{M}$ was added. After $15 \mathrm{~min}, 50 \mathrm{~mL}$ of sodium hydroxide $1 \mathrm{M}$ were added. The absorbance was immediately measured at $610 \mathrm{~nm}$, having the Gallic acid as positive control. Results were recorded as scavenging percentage [57]. All assays were performed three times in triplicate $(n=3)$.

\subsubsection{Superoxide Radical Scavenging Activity Assay}

The superoxide radical scavenging activity of the dextrans was investigated through the inhibition of the photochemical reduction of the nitroblue tetrazolium (NBT) in the riboflavin-light-NBT system. The dextrans $(50 \mathrm{mM}$ ) were added to a solution of phosphate buffer $50 \mathrm{mM}$ (pH 7.8), riboflavin $2 \mathrm{mM}$, EDTA $100 \mathrm{mM}$, L-methionine $13 \mathrm{mM}$ and NBT $75 \mathrm{mM}$. The formation of blue formazan was monitored by the increase in absorbance at $560 \mathrm{~nm}$ after the exposure to light for $10 \mathrm{~min}$ in a closed box. An identical reaction was maintained in the dark and served as a blank. Gallic acid was used as positive control. Results were recorded as scavenging percentage [43]. All assays were performed three times in triplicate $(n=3)$.

\subsection{Mitochondrial Reduction of MTT}

The cytotoxicity of the dextrans was evaluated following the mitochondrial reduction of the MTT. Briefly, the assay was conducted to investigate the cellular enzyme's capacity of reducing the 3-(4,5-dimethylthiazol-2-yl)-2,5-diphenyltetrazolium bromide (MTT) to formazan in RAW 264.7 macrophages with an active metabolism. The cells were incubated with the dextrans $(50 \mathrm{mM})$ at $37^{\circ} \mathrm{C}$ in the presence of DMEM for $24 \mathrm{~h}$. After incubation, traces of dextrans were removed by washing the cells twice with $200 \mu \mathrm{L}$ PBS and applying MTT $(1 \mathrm{mg} / \mathrm{mL})$ dissolved in $100 \mu \mathrm{L}$ of fresh medium to determine the effects of the samples on cell viability. Cells were then incubated for $4 \mathrm{~h}$ at $37^{\circ} \mathrm{C}$, in $5 \% \mathrm{CO}_{2}$. The MTT-formazan product dissolved in $100 \mu \mathrm{L}$ of ethanol was estimated by measuring the absorbance at $570 \mathrm{~nm}$ in a Multiskan Ascent Microplate Reader. Inhibition of MTT reduction is presented as a percentage of cell proliferation under no treatment conditions. Absorbance was measured at $570 \mathrm{~nm}$ [43].

\subsection{Production of Nitric Oxide (NO)}

To determine the effect of glucans in the amount of nitric oxide (NO) released by the RAW cells, the method described by Alves and collaborators [54] was used. Briefly, macrophages (RAW 264.7 cell line) were incubated $\left(3 \times 10^{5}\right.$ cells/well) in culture plates of 24 wells at $37^{\circ} \mathrm{C}$ in $\mathrm{CO}_{2} 5 \%$ both with and without lipopolysaccharides (LPS) in the presence of dextrans (50 mM). After $24 \mathrm{~h}$ a reaction with Griess reagent was conducted on the supernatant. The absorbance of the reaction was monitored at $540 \mathrm{~nm}$.

\subsection{Anticoagulant Assays}

The anticoagulant activity of the glucans was evaluated using two in vitro tests: the activated partial thromboplastin time (aPTT) and the prothrombin time (PT). Both assays were conducted in the $50 \mathrm{mM}$ concentration for all samples. The aPTT and PT assays were conducted following specification of the manufacturers (Labtest, Sao Paulo, SP, Brazil) and each assay was performed three times in triplicate $(n=3)$. 


\subsubsection{Activated Partial Thromboplastin Time (aPTT)}

The coagulation assay via activated partial thromboplastin time (aPTT) was conducted using normal human plasma treated with citrate in which the dextrans were incubated. Briefly, dextrans were mixed with the plasma treated with citrate and then incubated at $37^{\circ} \mathrm{C}$. After $3 \mathrm{~min}$, cephalin was added and the reaction was once again incubated. Following another $3 \mathrm{~min}, \mathrm{CaCl}_{2}(100 \mu \mathrm{L}, 20 \mathrm{mM})$ was added and the coagulation time was measured by the coagulometer. Clexane ${ }^{\circledR}$ (Sanofi Aventis Farmacêutica Ltda, São Paulo, SP, Brazil) and normal human plasma treated with citrate were used both as standard and control, respectively [54]. All assays were performed three times in triplicate $(n=3)$.

\subsubsection{Prothrombin Time (PT)}

The coagulation assay via prothrombin time (PT) was also conducted using normal human plasma treated with citrate, incubated along with the samples. Briefly, the dextrans were mixed with normal human plasma treated with citrate and incubated at $37^{\circ} \mathrm{C}$ for $3 \mathrm{~min}$. Then, soluplastin was added and the coagulation time was measured by the coagulometer [30].

\subsection{Statistical Analyses}

All data have been expressed as the average \pm standard deviation. Statistical analyses were conducted via a simple variation analyses (one-way ANOVA) followed by the Tukey-Kramer $(p<0.05)$ test. All tests were conducted on the GraphPad Prism 5.01 (GraphPad Softwares, La Jolla, CA, USA).

\section{Conclusions}

Dextrans D10, D40 and D147 are the same type of polysaccharide and their only difference is their molecular weight. They are formed by glucose in the alpha configuration and are free of protein and phenolic contaminants. The same dextran molecules-but with different molecular weights-showed different antioxidant and immunomodulatory activities. In one antioxidant test, the dextran activity increases according to the increase of the molecular weight. In another test, however, the activity might decrease or show no correlation to the molecular weight. It can be further stated that antioxidant dextrans act mainly in the termination of the formation process for reactive species. The great highlight of this study was the D40 dextrans, which presented with antioxidant activity in most of the tests conducted and showed a greater inhibiting activity of the lipid peroxidation: it presented with a greater hydrogen peroxide scavenging capacity when compared to the two other dextrans and it was also the only one to present with immunomodulatory activity. This points to the observation that, in order to attain dextrans that present with excellent immunomodulatory and antioxidant activity, one must find dextrans with molecular weight around $40 \mathrm{kDa}$. However, more studies, tests and published data are required to confirm this hypothesis. Therefore, future studies hold the intent to best characterize the immunomodulatory and antioxidant activities of D40 dextrans—or other dextrans with similar molecular weights.

Acknowledgments: The authors wish to thank Conselho Nacional de Desenvolvimento Científico e Tecnológico CNPq (National Council for Scientific and Technological Advancement, in loose translation), Coordenacão de Aperfeiçoamento Pessoal de Nível Superior CAPES (Higher Level Personal Development Coordination, in loose translation) and the Ministerio de Ciência, Tecnologia e Informação (MCTI-the Science and Technology Ministry in Brazil), for the financial support. Maria L. P. M. Grilo had a scientific initiation scholarship from CAPES. Hugo A. O. Rocha is a CNPq fellowship honored researcher. Vinicius C. Soeiro and Karoline R. T. Melo have a Ph.D. scholarship from CAPES. Jailma Almeida-Lima has a Post-doctorate scholarship from CAPES.

Author Contributions: Vinicius C. Soeiro prepared the samples and performed the chemical analysis. Vinicius C. Soeiro and Maria L. P. M. Grilo performed the antioxidant tests. Vinicius C. Soeiro, Karoline R. T. Melo and Jailma Almeida-Lima performed the immunomodulatory assays. Vinicius C. Soeiro and Monique G. C. F. Alves performed the anticoagulant tests. Mayara J. C. Medeiros and Daniel L. Pontes performed the FTIR analysis. Vinicius C. Soeiro analyzed all the data. Vinicius C. Soeiro, Leandro S. Costa and Hugo A. O. Rocha wrote the paper. Hugo A. O. Rocha funds and revised the paper. 
Conflicts of Interest: The authors declare no conflict of interest.

\section{References}

1. Ferreira, I.C.F.R.; Heleno, S.A.; Reis, F.S.; Stojkovic, D.; Queiroz, M.J.R.P.; Vasconcelos, M.H.; Sokovic, M. Chemical features of Ganoderma polysaccharides with antioxidant, antitumor and antimicrobial activities. Phytochemistry 2014, 114, 38-55. [PubMed]

2. Kagimura, F.Y.; Cunha, M.A.A.; Barbosa, A.M.; Dekker, R.F.H.; Malfatti, C.R.M. Biological activities of derivatized D-glucans: A review. Int. J. Biol. Macromol. 2015, 72, 588-598. [PubMed]

3. D'Hulst, C.; Mérida, A. The priming of storage glucan synthesis from bacteria to plants: Current knowledge and new developments. New Phytol. 2010, 188, 13-21. [PubMed]

4. Badel, S.; Bernardi, T.; Michaud, P. New perspectives for Lactobacilli exopolysaccharides. Biotechnol. Adv. 2011, 29, 54-66. [CrossRef] [PubMed]

5. Giavasis, I. Bioactive fungal polysaccharides as potential functional ingredients in food and nutraceuticals. Curr. Opin. Biotechnol. 2014, 26, 162-173. [CrossRef] [PubMed]

6. Freitas, F.; Alves, V.D.; Reis, M.A.M. Advances in bacterial exopolysaccharides: From production to biotechnological applications. Trends Biotechnol. 2011, 29, 388-398. [CrossRef] [PubMed]

7. Synytsya, A.; Novák, M. Structural diversity of fungal glucans. Carbohydr. Polym. 2013, 92, 792-809. [CrossRef] [PubMed]

8. Hong, J.-H.; Jung, H.K. Antioxidant and antitumor activities of $\beta$-glucan-rich exopolysaccharides with different molecular weight from Paenibacillus polymyxa JB115. J. Korean Soc. Appl. Biol. Chem. 2014, 57, 105-112. [CrossRef]

9. Queiroz, E.A.I.F.; Fortes, Z.B.; Cunha, M.A.A.; Barbosa, A.M.; Khaper, N.; Dekker, R.F.H. Antiproliferative and pro-apoptotic effects of three fungal exocellular $\beta$-glucans in MCF-7 breast cancer cells is mediated by oxidative stress, AMP-activated protein kinase (AMPK) and the Forkhead transcription factor, FOXO3a. Int. J. Biochem. Cell Biol. 2015, 67, 14-24. [CrossRef] [PubMed]

10. Silveira, M.L.L.; Smiderle, F.R.; Moraes, C.P.; Borato, D.G.; Baggio, C.H.; Ruthes, A.C.; Wisbeck, E.; Sassaki, G.L.; Cipriani, T.R.; Furlan, S.A.; et al. Structural characterization and anti-inflammatory activity of a linear $\beta$-D-glucan isolated from Pleurotus Sajor-Caju. Carbohydr. Polym. 2014, 113, 588-596. [CrossRef] [PubMed]

11. Maity, P.; Sen, I.K.; Maji, P.K.; Paloi, S.; Devi, K.S.P.; Acharya, K.; Maiti, T.K.; Islam, S.S. Structural, immunological, and antioxidant studies of $\beta$-glucan from edible mushroom Entoloma lividoalbum. Carbohydr. Polym. 2015, 123, 350-358. [CrossRef] [PubMed]

12. Ruthes, A.C.; Carbonero, E.R.; Córdova, M.M.; Baggio, C.H.; Sassaki, G.L.; Gorin, P.A.J.; Santos, A.R.S.; Iacomini, M. Fucomannogalactan and glucan from mushroom Amanita muscaria: Structure and inflammatory pain inhibition. Carbohydr. Polym. 2013, 98, 761-769. [CrossRef] [PubMed]

13. Maity, P.; Samanta, S.; Nandi, A.K.; Sen, I.K.; Paloi, S.; Acharya, K.; Islam, S.S. Structure elucidation and antioxidant properties of a soluble $\beta$-D-glucan from mushroom Entoloma lividoalbum. Int. J. Biol. Macromol. 2014, 63, 140-149. [CrossRef] [PubMed]

14. Roach, P.J.; Depaoli-Roach, A.A.; Hurley, T.D.; Tagliabracci, V.S. Glycogen and its metabolism: Some new developments and old themes. Biochem. J. 2012, 441, 763-787. [CrossRef] [PubMed]

15. Pérez, S.; Bertoft, E. The molecular structures of starch components and their contribution to the architecture of starch granules: A comprehensive review. Starch Staerke 2010, 62, 389-420. [CrossRef]

16. Buddana, S.K.; Varanasi, Y.V.N.; Shetty, P.R. Fibrinolytic, anti-inflammatory and anti-microbial properties of $\alpha$-(1-3)-glucans produced from Streptococcus mutans (MTCC 497). Carbohydr. Polym. 2015, 115, 152-159. [CrossRef] [PubMed]

17. Zhu, R.; Zhang, X.; Liu, W.; Zhou, Y.; Ding, R.; Yao, W.; Gao, X. Preparation and immunomodulating activities of a library of low-molecular-weight $\alpha$-glucans. Carbohydr. Polym. 2014, 111, 744-752. [CrossRef] [PubMed]

18. Gao, T.; Ma, S.; Song, J.; Bi, H.; Tao, Y. Antioxidant and immunological activities of water-soluble polysaccharides from Aconitum kusnezoffii Reichb. Int. J. Biol. Macromol. 2011, 49, 580-586. [CrossRef] [PubMed]

19. Ustyuzhanina, N.E.; Bilan, M.I.; Ushakova, N.A.; Usov, A.I.; Kiselevskiy, M.V.; Nifantiev, N.E. Fucoidans: Pro- or antiangiogenic agents? Glycobiology 2014, 24, 1265-1274. [CrossRef] [PubMed] 
20. Kelishomi, Z.H.; Goliaei, B.; Mahdavi, H.; Nikoofar, A.; Rahimi, M.; Moosavi-Movahedi, A.A.; Mamashli, F.; Bigdeli, B. Antioxidant activity of low molecular weight alginate produced by thermal treatment. Food Chem. 2016, 196, 897-902. [CrossRef] [PubMed]

21. Karbownik, M.S.; Nowa, J.Z. Hyaluronan: Towards novel anti-cancer therapeutics. Pharmacol. Rep. 2013, 65, 1056-1074. [CrossRef]

22. Zhu, Y.; Yao, Y.; Gao, Y.; Hu, Y.; Shi, Z.; Ren, G. Suppressive effects of barley $\beta$-glucans with different molecular weight on 3T3-L1 adipocyte differentiation. J. Food Sci. 2016, 81, H786-H793. [CrossRef] [PubMed]

23. Park, J.H.; Lim, M.S.; Woo, J.R.; Kim, J.W.; Lee, G.M. The molecular weight and concentration of dextran sulfate affect cell growth and antibody production in CHO cell cultures. Biotechnol. Prog. 2016. [CrossRef] [PubMed]

24. Falconer, D.J.; Mukerjea, R.; Robyt, J.F. Biosynthesis of dextrans with different molecular weights by selecting the concentration of Leuconostoc mesenteroides B-512FMC dextransucrase, the sucrose concentration, and the temperature. Carbohydr. Res. 2011, 346, 280-284. [CrossRef] [PubMed]

25. Masuelli, M.A. Dextrans in Aqueous Solution. Experimental Review on Intrinsic Viscosity Measurements and Temperature Effect. J. Polym. Biopolym. Phys. Chem. 2013, 1, 13-21.

26. Bhavani, A.L.; Nisha, J. Dextran-The polysaccharide with versatile uses. Int. J. Pharm. Bio Sci. 2010, 1, 569-573.

27. Zhao, P.; Upadhaya, S.D.; Li, J.; Kim, I. Comparison effects of dietary iron dextran and bacterial-iron supplementation on growth performance, fecal microbial flora, and blood profiles in sows and their litters. Anim. Sci. J. 2015, 86, 937-942. [CrossRef] [PubMed]

28. Aman, A.; Siddiqui, N.N.; Qader, S.A.U. Characterization and potential applications of high molecular weight dextran produced by Leuconostoc mesenteroides AA1. Carbohydr. Polym. 2012, 87, 910-915. [CrossRef]

29. Shukla, R.; Shukla, S.; Bivolarski, V.; Iliev, I.; Ivanova, I.; Goyal, A. Structural characterization of insoluble dextran produced by Leuconostoc mesenteroides NRRL B-1149 in the presence of maltose. Food Technol. Biotechnol. 2011, 49, 291-296.

30. Camara, R.B.G.; Costa, L.S.; Fidelis, G.P.; Nobre, L.T.D.B.; Dantas-Santos, N.; Cordeiro, S.L.; Costa, M.S.S.P.; Alves, L.G.; Rocha, H.A.O. Heterofucans from the brown seaweed Canistrocarpus cervicornis with anticoagulant and antioxidant Activities. Mar. Drugs 2011, 9, 124-138. [CrossRef] [PubMed]

31. Fernandes-Queiroz, M.; Teodosio-Melo, K.R.; Sabry, D.A.; Sassaki, G.L.; Rocha, H.A.O. Does the use of chitosan contribute to oxalate kidney stone formation? Mar. Drugs 2014, 13, 141-158. [CrossRef] [PubMed]

32. Silva, J.M.C.; Dantas-Santos, N.; Gomes, D.L.; Costa, L.S.; Cordeiro, S.L.; Costa, M.S.S.P.; Silva, N.B.; Freitas, M.L.; Scortecci, K.C.; Leite, E.L.; et al. Biological activities of the sulfated polysaccharide from the vascular plant Halodule wrightii. Rev. Brasil. Farmacogn. 2012, 22, 94-101. [CrossRef]

33. Tao, Y.; Zhang, R.; Yang, W.; Liu, H.; Yang, H.; Zhao, Q. Carboxymethylated hyperbranched polysaccharide: Synthesis, solution properties, and fabrication of hydrogel. Carbohydr. Polym. 2015, 128, 179-187. [CrossRef] [PubMed]

34. Synytsya, A.; Novak, M. Structural analysis of glucans. Ann. Transl. Med. 2014, 2, 1-14.

35. Vettori, M.H.P.B.; Franchetti, S.M.M.; Contiero, J. Structural characterization of a new dextran with a low degree of branching produced by Leuconostoc mesenteroides FT045B dextransucrase. Carbohydr. Polym. 2012, 88, 1440-1444. [CrossRef]

36. Suflet, D.M.; Chitanu, G.C.; Desbrires, J. Phosphorylated polysaccharides. 2. Synthesis and properties of phosphorylated dextran. Carbohydr. Polym. 2010, 82, 1271-1277. [CrossRef]

37. Kumar, S.; Pandey, A.K. Chemistry and Biological Activities of Flavonoids: An Overview. Sci. World J. 2013, 1-16. [CrossRef] [PubMed]

38. Kim, S.K.; Wijesekara, I. Development and biological activities of marine-derived bioactive peptides: A review. J. Funct. Foods 2010, 2, 1-9. [CrossRef]

39. Zhang, Z.; Wang, F.; Wang, X.; Liu, X.; Hou, Y.; Zhang, Q. Extraction of the polysaccharides from five algae and their potential antioxidant activity in vitro. Carbohydr. Polym. 2010, 82, 118-121. [CrossRef]

40. Melo-Silveira, R.F.; Fidelis, G.P.; Pereira Costa, M.S.S.; Telles, C.B.S.; Dantas-Santos, N.; Elias, S.O.; Ribeiro, V.B.; Barth, A.L.; Macedo, A.J.; Leite, E.L.; et al. In vitro antioxidant, anticoagulant and antimicrobial activity and in inhibition of cancer cell proliferation by xylan extracted from corn cobs. Int. J. Mol. Sci. 2012, 13, 409-426. [CrossRef] [PubMed]

41. Bartosz, G. Total antioxidant capacity. Adv. Clin. Chem. 2003, 37, 2423. 
42. Liu, W.; Wang, H.; Pang, X.; Yao, W.; Gao, X. Characterization and antioxidant activity of two low-molecular-weight polysaccharides purified from the fruiting bodies of Ganoderma lucidum. Int. J. Biol. Macromol. 2010, 46, 451-457. [CrossRef] [PubMed]

43. Melo-Silveira, R.F.; Fidelis, G.P.; Viana, R.L.S.; Soeiro, V.C.; Silva, R.A.S.; Machado, D.; Costa, L.S.; Ferreira, C.V.; Rocha, H.A.O. Antioxidant and Antiproliferative Activities of Methanolic Extract from a Neglected Agricultural Product: Corn Cobs. Molecules 2014, 19, 5360-5378. [CrossRef] [PubMed]

44. Giese, E.C.; Gascon, J.; Anzelmo, G.; Barbosa, A.M.; da Cunha, M.A.A.; Dekker, R.F.H. Free-radical scavenging properties and antioxidant activities of botryosphaeran and some other $\beta$-D-glucans. Int. J. Biol. Macromol. 2015, 72, 125-130. [CrossRef] [PubMed]

45. Deng, C.; Hu, Z.; Fu, H.; Hu, M.; Xu, X.; Chen, J. Chemical analysis and antioxidant activity in vitro of a $\beta$-D-glucan isolated from Dictyophora indusiata. Int. J. Biol. Macromol. 2012, 51, 70-75. [CrossRef] [PubMed]

46. Kozarski, M.; Klaus, A.; Niksic, M.; Jakovljevic, D.; Helsper, J.P.F.G.; Van Griensven, L.J.L.D. Antioxidative and immunomodulating activities of polysaccharide extracts of the medicinal mushrooms Agaricus bisporus, Agaricus brasiliensis, Ganoderma lucidum and Phellinus linteus. Food Chem. 2011, 129, 1667-1675. [CrossRef]

47. Han-dan, R.; Chuan-ren, D.; Hong, L. The Effects of Normovolemic Hemodilution with Dextran-40 on Acute Myocardial Ischemia/Reperfusion Injury in Rabbits. J. Tongji Med. Univ. 1992, 12, 23-27. [CrossRef]

48. Kanner, J.; German, J.B.; Kinsella, J.E.; Hultin, H.O. Initiation of lipid peroxidation in biological systems. Crit. Rev. Food Sci. Nutr. 1987, 25, 317-364. [CrossRef] [PubMed]

49. Uttara, B.; Singh, A.V.; Zamboni, P.; Mahajan, R.T. Oxidative stress and neurodegenerative diseases: A review of upstream and downstream antioxidant therapeutic options. Curr. Neuropharmacol. 2009, 7, 65-74. [CrossRef] [PubMed]

50. Naessens, M.; Cerdobbel, A.; Soetaert, W.; Vandamme, E.J. Leuconostoc dextransucrase and dextran: Production, properties and applications. J. Chem. Technol. Biotechnol. 2005, 80, 845-860. [CrossRef]

51. Devi, K.S.P.; Roy, B.; Patra, P.; Sahoo, B.; Islam, S.S.; Maiti, T.K. Characterization and lectin microarray of an immunomodulatory heteroglucan from Pleurotus ostreatus mycelia. Carbohydr. Polym. 2013, 94, 857-865. [CrossRef] [PubMed]

52. Nworu, C.S.; Ihim, S.A.; Okoye, F.B.C.; Esimone, C.O.; Adikwu, M.U.; Akah, P.A. Immunomodulatory and immunorestorative activities of $\beta$-D-glucan-rich extract and polysaccharide fraction of mushroom, Pleurutus tuberregium. Pharm. Biol. 2015, 53, 1555-1566. [CrossRef] [PubMed]

53. Martinichen-herrero, J.C.; Rosechrer, E.; Albert, P.; Gorin, J.; Iacomini, M. Anticoagulant and antithrombotic activity of a sulfate obtained from a glucan component of the lichen Parmotrema mantiqueirense Hale. Carbohydr. Polym. 2005, 60, 7-13. [CrossRef]

54. Alves, M.G.C.F.; Almeida-Lima, J.; Paiva, A.A.O.; Leite, E.L.; Rocha, H.A.O. Extraction process optimization of sulfated galactan-rich fractions from Hypnea musciformis in order to obtain antioxidant, anticoagulant, or immunomodulatory polysaccharides. J. Appl. Phycol. 2016, 28, 1931-1942.

55. Magalhaes, K.D.; Costa, L.S.; Fidelis, G.P.; Oliveira, R.M.; Nobre, L.T.D.B.; Dantas-Santos, N.; Camara, R.B.G.; Albuquerque, I.R.L.; Cordeiro, S.L.; Sabry, D.A.; et al. Anticoagulant, Antioxidant and Antitumor Activities of Heterofucans from the Seaweed Dictyopteris delicatula. Int. J. Mol. Sci. 2011, 12, 3352-3365. [CrossRef] [PubMed]

56. Dapkevicius, A.; Venskutonis, R.; Van Beek, T.A.; Linssen, J.P.H. Antioxidant activity of extracts obtained by different isolation procedures from some aromatic herbs grown in Lithuania. J. Sci. Food Agric. 1998, 77, 140-146. [CrossRef]

57. Sroka, Z.; Cisowski, W. Hydrogen peroxide scavenging, antioxidant and anti-radical activity of some phenolic acids. Food Chem. Toxicol. 2003, 41, 753-758. [CrossRef]

(C) 2016 by the authors; licensee MDPI, Basel, Switzerland. This article is an open access article distributed under the terms and conditions of the Creative Commons Attribution (CC-BY) license (http:/ / creativecommons.org/licenses/by/4.0/). 